\title{
Depression, anxiety, and stress among Ugandan university students during the COVID-19 lockdown: an online survey
}

\author{
Sarah Maria Najjuka ${ }^{1}$, Gaudencia Checkwech ${ }^{1}$, Ronald Olum ${ }^{1}$, Scholastic Ashaba ${ }^{2}$, Mark Mohan Kaggwa ${ }^{2,3}$
}

1. Makerere University, College of Health Sciences, Uganda, P.O. Box 7062, Kampala.

2. Mbarara University of Science and Technology, Department of Psychiatry, Uganda, P. O. Box 1410, Mbarara. 3. African Centre for Suicide Prevention and Research, Mbarara, Uganda.

\begin{abstract}
Background: COVID19 pandemic forced most countries to lockdown, leading to the prolonged closure of many learning institutions. This dramatic shift led to increase of mental illness symptoms among university students.

Objective: To determine the prevalence and factors associated with symptoms of depression, anxiety, and stress among Uganda's university students during the COVID-19 lockdown.

Methods: We conducted a one-month online survey using the Depression Anxiety and Stress Scale (DASS-21).

Results: Participants $\mathrm{n}=321$ were enrolled with mean age, 24.8(SD=5.1) years and 198(61.7\%) were males. The prevalence of mental health symptoms among participants was $80.7 \%, 98.4 \%$, and $77.9 \%$ for depression, high levels of anxiety, and stress, respectively. Statistically significant association between mental health symptoms on multi-logistic regression was found with Males (depression=2.97[1.61-5.48] and stress=1.90[1.07-3.35]), engagement in leisure activity (depression $=1.87[1.01-3.49]$ and stress $=1.98[1.10-3.56])$, and being finalist (stress $=0.55[0.31-0.97])$. Use of addictive substances seem to potentially alleviate symptoms of depression, anxiety and stress in the short term.

Conclusions: The findings of this study suggest a high prevalence of symptoms of depression, anxiety and stress among university students during the COVID-19 lockdown. Students' mental health should be monitored by all stakeholders, especially as the pandemic progresses.

Keywords: COVID-19 lockdown; University students; Mental health.

DOI: bttps://dx.doi.org/10.4314/abs.v21it.6

Cite as: Naijuka SM, Checkwech G, Olum R, Ashaba S, Kaggwa MM. Depression, anxiety, and stress among Ugandan university students during the COVID-19 lockdown: an online survey. Afri Health Sci. 2021;21(4):1533-43. bttps:// dx.doi.org/10.4314/abs.v21i4.6
\end{abstract}

\section{Introduction}

Coronavirus disease 2019 (COVID-19) is an acute respiratory disease caused by a novel human coronavirus (SARS-Cov-2); which was declared a pandemic by March $2020^{1,2}$. Its highly contagious nature prompted the implementation of strict infection control measures in countries that had reported cases of the disease ${ }^{3}$. Before the first case of COVID-19 on 21 March 2020 in Uganda, a national lockdown similar to other African countries was declared, which involved the complete closure of learning-institutions to control the spread of the coronavirus ${ }^{4-6}$. Nevertheless, the escalating mortal-
Corresponding author:
Mark Mohan Kaggwa
Department of Psychiatry,
Faculty of Medicine, Mbarara University
of Science and Technology, Uganda.
P. O. Box 1410, Mbarara
Email:kmarkmohan@gmail.com

ity rates of COVID-19 globally led to the prolonged closure of schools and universities; that documented social and psychological effects including loss of hope, uncertainty about the future of education, loneliness, and social isolation among university students ${ }^{7,8}$.

Previous studies have reported increasing levels of depression, anxiety, and stress among university students as the COVID-19 pandemic persists ${ }^{9-11}$. One study conducted among university students in China between January $31^{\text {st }}$ and February $5^{\text {th }} 2020$, found the prevalence of anxiety and depression symptoms at $7.7 \%$ and $12.2 \%$, respectively ${ }^{12}$. In another study carried out in Italy between 24 March and 3 May, it was observed that $34.3 \%$ and $27.8 \%$ of students had anxiety and depressive symptoms, respectively ${ }^{13}$. In Bangladesh, the prevalence of depressive and anxiety symptoms were much higher among University students, $82.4 \%$ and $87.7 \%$, respectively in a study conducted from May $6^{\text {th }}$ $-12^{\text {th }}, 2020^{14}$. Likewise, very high levels of stress have also been reported among university students around 
the globe during the pandemic ${ }^{7,15,16}$. A high prevalence of mental symptoms (depression, anxiety, and stress) among students is associated with higher rates of burnout, suicide, dropout, and poor academic performance $^{11,17-22}$.

Living in urban areas, being from a family with a stable income, and students living with parents have been documented to be protective against anxiety, whereas having relatives or acquaintances with COVID-19 increases the risk for anxiety ${ }^{23}$. Also, the use of the official channels as the main source of information about COVID-19 is documented as a protective factor for both anxiety and depression. On the other hand, the fear of the risk of exposure was found to be significantly associated with a high risk of having mental illness symptoms ${ }^{24,25}$. Moreover, students who anticipated participating in events such as exchange programs and graduation ceremonies (finalists) were more stressed following the closure of institutions of learning ${ }^{26}$. During the pandemic use of substances of addiction (alcohol, cannabis, tobacco, and prescription medication) increased drastically, especially among university students ${ }^{27-29}$. These substances of addiction have been associated with increased mental illness symptoms among university students during the pandemic ${ }^{27-30}$. Other factors that have been identified to be associated with mental symptoms during the pandemic include gender (female), lack of interest towards studying, not having close friends, not having active leisure activities, family history of mental illness, and conflict with friends ${ }^{14,31,32}$.

Despite the challenges of a national lockdown, including the mandate for social distancing and persistent closure of institutions of learning; information is limited about the mental health of Ugandan university students whose academic progress was halted. Specifically, there were no Ugandan universities that continued with online learning formats which resulted in an abrupt cessation of learning for all learners in the country as a way to prevent the spread of the COVID-19. This specific study aimed at screening for the mental illness symptoms of students by assessing symptoms of depression, anxiety, and stress during the COVID19 lockdown in Uganda.

\section{Methods}

\section{Study design and procedure}

Due to the increasing psychological changes associated with the pandemic, a one-month online survey from June 29, 2020, to July 29, 2020, was conducted. A semi-structured questionnaire using Google forms (https:// forms.gle/nqfZCR55g9jLFSqV8), was developed, and posted in various WhatsApp groups of university students across the country. Respondents were recruited by a convenience sampling strategy focused on recruiting students all over the country during the COVID-19 lockdown. The students on the study group sent a link with this message "Hi, I am (name of student), a student at (university). As universities plan to reopen, the mental health of university students during the COVID-19 pandemic in Uganda should be known to inform adequate planning. Please help me take some time and fill in this form and send it to any other university students or university student groups". Those who voluntarily accepted to participate clicked on the link to access the questionnaire. This method was preferred since the universities were closed, thereby excluding universities from the process of identifying students and distributing the survey. The design of the questionnaire permitted only eligible participants to participate in the study; that is, students 18-years and above.

\section{Ethical considerations}

The study was approved by the Mulago Hospital Research and Ethics Committee under the reference number MHREC 1875. All participants provided informed consent.

\section{Study site and population}

There are 9 public and 41 private universities in Uganda33. The study participants were part of approximately 692,490 students who were enrolled in universities from 2013 to 2019 and consisted of finalists (students in their last year of study, for instance, second year, third year, fourth year, or fifth years depending on the academic program), semi-finalists, international students, among others from various of faculties of the respective universities ${ }^{33}$.

\section{Sample size}

The minimal sample size required to produce statistical power of $80 \%$ was calculated using Epi Info StatCalc for population surveys version 7.2.2.6. Using a population size of approximately 700,000 university students in Uganda as of 2019, expected frequency of depression as a primary outcome at $50 \%$, acceptable margin of error of 5\% and design effect of 1.0, the minimum calculated sample size was 382 .

\section{Data collection}

Data were collected using a comprehensive questionnaire that consisted of different sections. The first section included socio-demographic characteristics that in- 
cluded: age, sex, marital status, religion, current district of residence, number of people they are staying with and the relationships, university, level of study (undergraduate or postgraduate), year of study, and special groups [finalist, international students, semi-finalists, and those who stayed at university premises after lockdown], the form of sponsorship (self or government), current use of a substance of addiction (alcohol, cannabis, cigarettes), current employment status, sources of financial support during the lockdown, history of any mental, and chronic illness). The second part of the questionnaire inquired about COVID-19 related variables, which included the source of knowledge about COVID-19, previous testing for COVID-19, positive COVID-19 test results, and having a friend/relative/ neighbour who had tested positive for COVID-19.

The third part of the questionnaire consisted of standardized Depression Anxiety and Stress Scale-21 (DASS$21)^{34}$. The DASS-21 is a free scale that consists of three simple self-report scales designed to measure more than one symptom of the emotional states of depression, anxiety, and stress with each scale containing seven items and divided into subscales with similar content. All subscales are rated on a four-point Likert scale type ranging from 0 (never) to 3 (almost always). The ranges for Depression are, normal $(0-9)$, mild $(10-$ $12)$, moderate $(13-20)$, severe $(21-27)$, and extremely severe (28 - 42); for Anxiety, normal (0 - 6), mild (7 $9)$, moderate $(10-14)$, severe $(15-19)$, and extremely severe $(20-42)$; and for Stress, normal $(0-10)$, mild $(11-18)$, moderate $(19-26)$, severe $(27-34)$, and ex- tremely severe $(35-42)$. The DASS-21 has been used in various COVID-19 mental illness studies all over the globe and has shown to be a valid and reliable scale for assessing these mental health symptoms of individuals during the COVID-19 pandemic ${ }^{35,36}$. Despite the scale not being used in Uganda before, it has been validated for use in other non-clinical groups in Africa (South Africa) and it has shown good construct validity, acceptability, discriminant validity, convergent validity and reliability ${ }^{37}$.

\section{Statistical analysis}

Descriptive statistics were used to present socio-demographic data, using the aforementioned cutoffs, the prevalence of symptoms of depression, anxiety, and stress was calculated. Depression and anxiety were classified as present (mild to extremely severe) and absent (normal), while anxiety was classified as higher (severe and extremely severe) and lower levels (mild and moderate). To determine the factors associated with depression, stress, and higher levels of anxiety, bivariate and multivariate logistic regression analyses were performed, Odds Ratios (OR) and 95\% confidence intervals (CI) were presented. For statistical significance, a P-level of less than 0.05 used.

\section{Results}

\section{Demographic Characteristics}

Data were collected from a total of 321 eligible participants. The participants were from 15 Ugandan universities, coming from most regions of the country (figure 1).

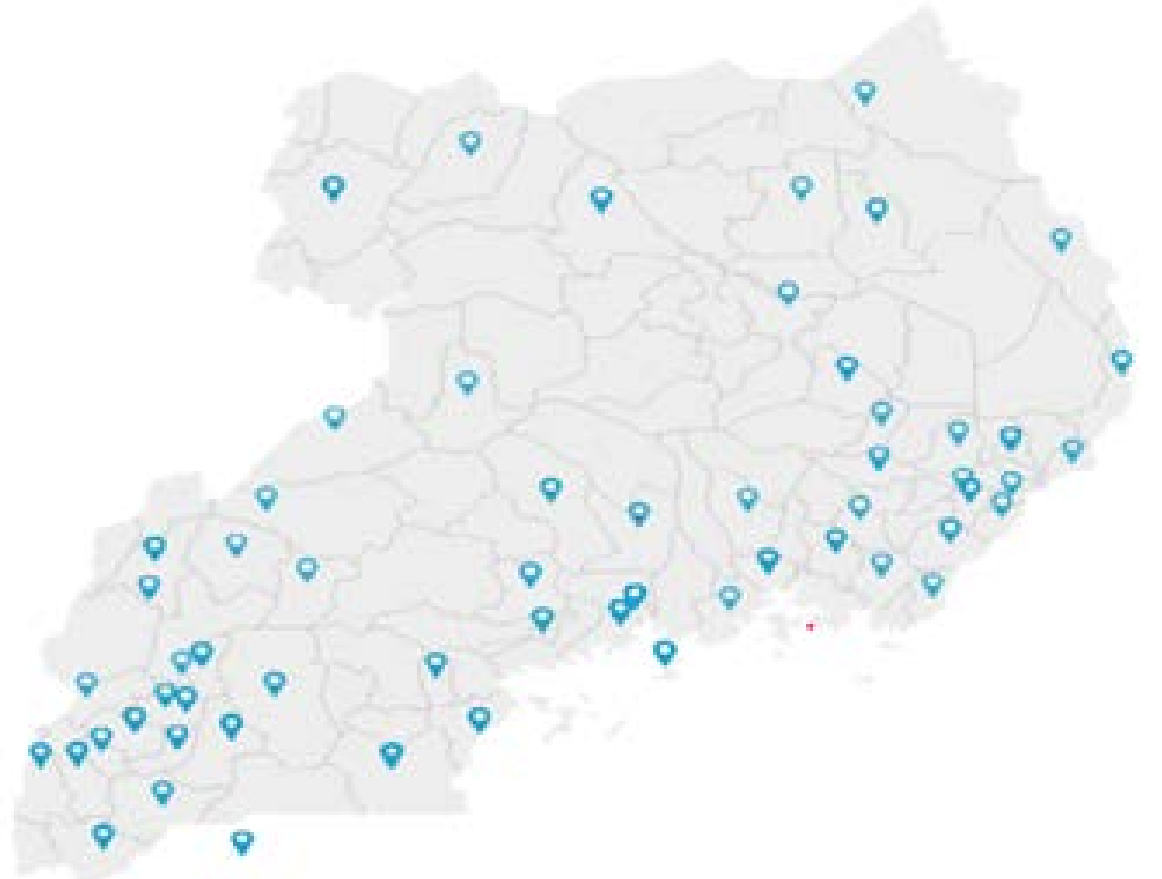

Figure 1: Maps of Uganda Showing the distribution of participants 
Of the sample, 123 were females, mean (standard deviation (SD)) age 24.8 (5.1) years; 56 of the participants $(17.5 \%)$ were married/cohabiting. The majority of the participants $(69.8 \%)$ stayed in urban centres during the pandemic and $24.9 \%$ from the capital city Kampala (the most affected district in the country). The undergraduate students (262) were $81.6 \%$; learners who had studied for three years represented $33.6 \%$ of the participants. Majority of the participants $n=169(52.6 \%)$ were doing medical-related courses. Table 1 presents additional demographic and pandemic-related characteristics.

Table 1: Descriptive Statistics of Demographic Characteristics and Pandemic-Related Information for the Total Sample

\begin{tabular}{|c|c|c|}
\hline \multicolumn{2}{|l|}{ Variable } & \multirow{2}{*}{$\begin{array}{l}N=321 \\
n(\%)\end{array}$} \\
\hline Age & $24.8(5.1)$ & \\
\hline \multirow[t]{2}{*}{ Sex } & Female & $123(38.3)$ \\
\hline & Male & $198(61.7)$ \\
\hline \multirow[t]{3}{*}{ Religion } & Christian & $283(88.2)$ \\
\hline & Islam & $28(8.7)$ \\
\hline & Others & $10(3.1)$ \\
\hline \multirow[t]{2}{*}{ Marital status } & Married/cohabiting & $56(17.5)$ \\
\hline & Single & $265(82.6)$ \\
\hline \multirow[t]{2}{*}{ Residence } & Rural & $97(30.2)$ \\
\hline & Urban & $224(69.8)$ \\
\hline \multirow[t]{2}{*}{ Education level } & Undergraduate & $273(86.4)$ \\
\hline & Post and Graduate & $43(11.7)$ \\
\hline \multirow[t]{5}{*}{ Year of study } & 1 & $47(14.6)$ \\
\hline & 2 & $87(27.1)$ \\
\hline & 3 & $108(33.6)$ \\
\hline & \begin{tabular}{|l}
4 \\
\end{tabular} & $60(18.7)$ \\
\hline & 5 & $19(5.9)$ \\
\hline \multirow[t]{3}{*}{ Sponsorship } & Government & $89(27.7)$ \\
\hline & Others & $34(10.6)$ \\
\hline & Private & $198(61.7)$ \\
\hline \multirow[t]{2}{*}{ Employment } & No & $256(79.8)$ \\
\hline & Yes & $65(20.2)$ \\
\hline \multirow[t]{2}{*}{ Finalist } & No & $199(62)$ \\
\hline & \begin{tabular}{|l} 
Yes \\
\end{tabular} & $122(38)$ \\
\hline \multirow[t]{2}{*}{ International students } & No & $301(93.8($ \\
\hline & Yes & $20(6.2)$ \\
\hline \multirow[t]{2}{*}{ Stayed at university during closure } & No & $288(89.7)$ \\
\hline & Yes & $33(10.3)$ \\
\hline \multirow[t]{2}{*}{ Semi-finalist } & No & $225(70.1)$ \\
\hline & Yes & $96(29.9)$ \\
\hline Number of people they currently live with [median (range)] & $14(1-20)$ & \\
\hline \multicolumn{3}{|l|}{ People they stay with in lockdown } \\
\hline \multirow[t]{2}{*}{ 1. Children } & No & $281(87.5)$ \\
\hline & Yes & $40(12.5)$ \\
\hline \multirow[t]{2}{*}{ 2. Friend } & No & $290(90.3)$ \\
\hline & Yes & $31(9.7)$ \\
\hline \multirow[t]{2}{*}{ 3. Parents } & No & $191(59.5)$ \\
\hline & Yes & $130(40.5)$ \\
\hline \multirow[t]{2}{*}{ 4. $\quad$ Relatives } & No & $160(49.8)$ \\
\hline & Yes & $161(50.2)$ \\
\hline \multirow[t]{2}{*}{ 5. Spouse } & No & $282(87.9)$ \\
\hline & \begin{tabular}{|l|l|} 
Yes \\
\end{tabular} & $39(12.2)$ \\
\hline \multirow[t]{2}{*}{ 6. Roommate } & No & $312(97.2)$ \\
\hline & Yes & $9(2.8)$ \\
\hline \multirow[t]{3}{*}{ Number of financial supporting sources } & 0 & $32(10)$ \\
\hline & 1 & $250(77.9)$ \\
\hline & 2 & $35(10.9)$ \\
\hline
\end{tabular}




\begin{tabular}{|c|c|c|}
\hline & 3 & $4(1.2)$ \\
\hline \multirow[t]{2}{*}{ Leisure activity involvement during lockdown } & No & $179(55.8)$ \\
\hline & Yes & $142(47.2)$ \\
\hline \multirow[t]{2}{*}{ History of mental illness } & Yes & $290(90)$ \\
\hline & No & $31(10)$ \\
\hline \multirow[t]{2}{*}{ History of chronic illness } & No & $289(90)$ \\
\hline & yes & $32(10)$ \\
\hline \multirow[t]{2}{*}{ Current use of a Substance of addiction } & No & $256(80.2)$ \\
\hline & Yes & $63(19.8)$ \\
\hline 1. Alcohol & \multicolumn{2}{|c|}{$48(15)$} \\
\hline 2. Caffeine & \multicolumn{2}{|c|}{$17(5.3)$} \\
\hline 3. Cannabis & \multicolumn{2}{|c|}{$3(0.9)$} \\
\hline 4. Cigarette & \multirow{2}{*}{\multicolumn{2}{|c|}{$\frac{2(0.6)}{2(0.6)}$}} \\
\hline 5. Others & & \\
\hline
\end{tabular}

Prevalence of symptoms of depression, anxiety, and stress

The prevalence of symptoms for the three mental health conditions among the total sample was $80.7 \%$ for depression $(\mathrm{n}=259$, including $35[10.9 \%]$ with mild, 134 [41.7] with moderate, 90 [28.0\%] with severe, and none with extremely severe depression). A total of 316 (98.4\%) participants had symptoms of anxiety, including $11[3.4 \%]$ with mild and 59 [18.4] with moderate that is, low levels of anxiety, 80 [24.9] with severe and 166 participants $[51.7 \%]$ with extremely severe anxiety that is, high levels of anxiety. For stress $n=250$ (77.9\%), including 120 [37.4\%] with mild, 130 [40.5], no participants with severe and extremely severe stress.

Factors associated with symptoms of depression, stress, and higher levels of anxiety

Table 2 presents the results of the unadjusted analysis of demographic and pandemic-related variables. In the multivariable analysis, factors associated with the symptoms of depression and stress were male sex, having a leisure activity during the lockdown, and the use of addictive substances. Using addictive substances was protective against higher levels of anxiety in the population (AOR, 0.50; 95\% CI, $0.27-0.94$ ).

Table 2: Bivariable Regression Analysis of Factors Associated with Symptoms of Depression, Anxiety, and Stress

\begin{tabular}{|c|c|c|c|c|c|c|}
\hline \multirow[t]{2}{*}{ Variable } & \multicolumn{2}{|l|}{ Depression } & \multicolumn{2}{|c|}{ Higher levels of Anxiety } & \multicolumn{2}{|l|}{ Stress } \\
\hline & OR $(95 \% \mathrm{CI})$ & P value & OR $(95 \% \mathrm{CI})$ & P value & OR $(95 \% \mathrm{CI})$ & P value \\
\hline Age & $1.00(0.94-1.06)$ & 0.963 & $1.00(0.95-1.06)$ & 0.887 & $0.98(0.94-1.04)$ & 0.570 \\
\hline \multicolumn{7}{|l|}{ Sex } \\
\hline Male & $2.52(1.43-4.43)$ & 0.001 & $1.60(0.94-2.74)$ & 0.086 & $1.66(0.97-2.83)$ & 0.062 \\
\hline Female & 1 (reference) & & 1 (reference) & & 1 (reference) & \\
\hline \multicolumn{7}{|l|}{ Religion } \\
\hline Christian & $0.44(0.55-3.55)$ & 0.441 & $0.38(0.05-3.05)$ & 0.362 & $0.89(0.18-4.30)$ & 0.886 \\
\hline Islam & $0.67(0.06-6.79)$ & 0.732 & $0.41(0.04-3.88)$ & 0.435 & $0.75(0.13-4.40)$ & 0.750 \\
\hline Others & 1 (reference) & & 1 (reference) & & 1 (reference) & \\
\hline \multicolumn{7}{|l|}{ Marital status } \\
\hline Single & $1.02(0.50-2.12)$ & 0.945 & $1.14(0.57-2.27)$ & 0.709 & $1.22(0.62-2.38)$ & 0.568 \\
\hline Married/cohabiting & 1 (reference) & & 1 (reference) & & 1 (reference) & \\
\hline \multicolumn{7}{|l|}{ Residence } \\
\hline Urban & $1.12(0.62-2.04)$ & 0.697 & $1.49(0.85-2.6)$ & 0.165 & $1.46(0.83-2.54)$ & 0.185 \\
\hline Rural & 1 (reference) & & 1 (reference) & & 1 (reference) & \\
\hline \multicolumn{7}{|l|}{ Education level } \\
\hline Undergraduate & $1.09(0.49-2.40)$ & 0.837 & $0.78(0.34-1.76)$ & 0.548 & $1.20(0.57-2.53)$ & 0.620 \\
\hline Post and Graduate & 1 (reference) & & 1 (reference) & & 1 (reference) & \\
\hline \multicolumn{7}{|l|}{ Year of study } \\
\hline 1 & 1 (reference) & & 1 (reference) & & 1 (reference) & \\
\hline 2 & $0.46(0.16-1.32)$ & 0.148 & $0.81(0.34-1.89)$ & 0.624 & $1.14(0.45-2.84)$ & 0.784 \\
\hline 3 & $0.59(0.21-1.71)$ & 0.336 & $1.07(0.46-2.49)$ & 0.869 & $0.75(0.32-1.75)$ & 0.501 \\
\hline 4 & $0.30(0.10-0.89)$ & 0.030 & $1.21(0.46-3.16)$ & 0.694 & $0.65(0.26-1.64)$ & 0.364 \\
\hline
\end{tabular}




\begin{tabular}{|c|c|c|c|c|c|c|}
\hline 5 & $0.45(0.10-1.88)$ & 0.273 & $0.72(0.21-2.51)$ & 0.609 & $0.66(0.19-2.32)$ & 0.521 \\
\hline \multicolumn{7}{|l|}{ Sponsorships } \\
\hline Government & $0.93(0.50-1.72)$ & 0.824 & $1.17(0.63-2.20)$ & 0.615 & $1.11(0.61-2.04)$ & 0.724 \\
\hline Others & $2.62(0.76-8.99)$ & 0.127 & $0.80(0.35-1.85)$ & 0.608 & $1.41(0.55-3.62)$ & 0.472 \\
\hline Private & 1 (reference) & & 1 (reference) & & 1 (reference) & \\
\hline \multicolumn{7}{|l|}{ Employment } \\
\hline Yes & $1.07(0.53-2.15)$ & 0.845 & $1.15(0.58-2.25)$ & 0.692 & $1.17(0.59-2.30)$ & 0.645 \\
\hline No & 1 (reference) & & 1 (reference) & & 1 (reference) & \\
\hline \multicolumn{7}{|l|}{ Finalist } \\
\hline Yes & $0.54(0.31-0.95)$ & 0.032 & $0.60(0.35-1.03)$ & 0.989 & $0.51(0.30-0.87)$ & 0.013 \\
\hline No & 1 (reference) & & 1 (reference) & & 1 (reference) & \\
\hline \multicolumn{7}{|l|}{ International students } \\
\hline Yes & $1,38(0.39-4.87)$ & 0.615 & $0.84(0.30-2.41)$ & 0.752 & $0.84(0.29-2.40)$ & 0.749 \\
\hline No & 1 (reference) & & 1 (reference) & & 1 (reference) & \\
\hline \multicolumn{7}{|l|}{ Stayed at university during closure } \\
\hline Yes & $1.09(0.43-2.76)$ & 0.862 & $2.98(0.88-10.11)$ & 0.079 & $0.87(0.38-2.03)$ & 0.756 \\
\hline No & 1 (reference) & & 1 (reference) & & 1 (reference) & \\
\hline \multicolumn{7}{|l|}{ Semi-finalist } \\
\hline Yes & $1.05(0.57-1.94)$ & 0.867 & $1.77(0.94-3.32)$ & 0.077 & $1.47(0.80-2.69)$ & 0.215 \\
\hline No & 1 (reference) & & 1 (reference) & & 1 (reference) & \\
\hline $\begin{array}{l}\text { Number of people they currently } \\
\text { live with }\end{array}$ & $0.99(0.95-1.04)$ & 0.714 & $0.99(0.94-1.04)$ & 0.655 & $0.99(0.95-1.04)$ & 0.807 \\
\hline People they stay with in lockdown & & & & & & \\
\hline (1) Children & & & & & & \\
\hline Yes & $0.95(0.41-2.18)$ & 0.907 & $1.30(0.55-3.09)$ & 0.556 & $0.71(0.34-1.51)$ & 0.382 \\
\hline No & 1 (reference) & & 1 (reference) & & 1 (reference) & \\
\hline (2) Friend & & & & & & \\
\hline Yes & $1.27(0.47-3.46)$ & 0.637 & $1.54(0.57-4.16)$ & 0.398 & $2.03(0.68-6.0)$ & 0.202 \\
\hline No & 1 (reference) & & 1 (reference) & & 1 (reference) & \\
\hline No & 1 (reference) & & 1 (reference) & & 1 (reference) & \\
\hline (5) Spouse & & & & & & \\
\hline Yes & $1.12(0.46-2.64)$ & 0.818 & $0.87(0.39-1.94)$ & 0.735 & $0.94(0.42-2.08)$ & 0.878 \\
\hline No & 1 (reference) & & 1 (reference) & & 1 (reference) & \\
\hline (6) Roommate & & & & & & \\
\hline Yes & $1.94(0.24-15.84)$ & 0.534 & $0.56(0.14-2.29)$ & 0.419 & $0.99(0,20-4.89)$ & 0.994 \\
\hline No & 1 (reference) & & 1 (reference) & & 1 (reference) & \\
\hline Financial supporting sources & & & & & & \\
\hline Yes (1 - 3 sources) & $0.40(0.12-1.37)$ & 0.145 & $1.09(0.64-1.85)$ & 0.746 & $1.19(0.51-2.79)$ & 0.679 \\
\hline No & 1 (reference) & & 1 (reference) & & 1 (reference) & \\
\hline Leisure activity involvement durin & lockdown & & & & & \\
\hline Yes & $1.87(1.04-3.36)$ & 0.036 & $1.33(0.77-2.29)$ & 0.302 & $1.89(1.09-3.30)$ & 0.024 \\
\hline No & 1 (reference) & & 1 (reference) & & 1 (reference) & \\
\hline History of mental illness & & & & & & \\
\hline Yes & $1.19(0.44-3.24)$ & 0.736 & $0.56(0.25-1.25)$ & 0.158 & $0.62(0.27-1.43)$ & 0.265 \\
\hline No & 1 (reference) & & 1 (reference) & & 1 (reference) & \\
\hline Current use of a Substance of addi & tion & & & & & \\
\hline Yes & $0.26(0.14-0.47)$ & 0.001 & $0.50(0.27-0.94)$ & 0.030 & $0.27(0.15-0.49)$ & 0.001 \\
\hline No & 1 (reference) & & 1 (reference) & & 1 (reference) & \\
\hline History of chronic illness & & & & & & \\
\hline Yes & $1.19(0.44-3.24)$ & 0.736 & $0.97(0.40-2.36)$ & 0.952 & $0.75(0.32-1.76)$ & 0.510 \\
\hline No & 1 (reference) & & 1 (reference) & & 1 (reference) & \\
\hline Main source of information about & OVID 19 & & & & & \\
\hline Neighbours/peers/relatives & $0.30(0.05-1.94)$ & 0.205 & $1.28(0.14-12.1)$ & 0.830 & $0.26(0.05-1.45)$ & 0.123 \\
\hline Newspapers & $0.25(0.05-1.28)$ & 0.095 & $0.26(0.06-1.19)$ & 0.082 & $0.43(0.09-2.06)$ & 0.289 \\
\hline Social media & $0.53(0.21-1.33)$ & 0.177 & $0.78(0.35-1.72)$ & 0.535 & $0.82(0.37-1.82)$ & 0.624 \\
\hline Television & $0.66(0.25-1.70)$ & 0.388 & $0.98(0.43-2.26)$ & 0.968 & $1.13(0.48-2.63)$ & 0.779 \\
\hline WHO/CDC platforms & $1.12(0.35-3.58)$ & 0.852 & $1.19(0.45-3.18)$ & 0.723 & $1.38(0.50-3.75)$ & 0.534 \\
\hline Ministry of health platform & 1 (reference) & & 1 (reference) & & 1 (reference) & \\
\hline
\end{tabular}




\begin{tabular}{|c|c|c|c|c|c|c|}
\hline \multicolumn{7}{|c|}{ Having ever tested for COVID 19} \\
\hline Yes & $2.74(0.63-11.97)$ & 0.180 & $1.15(0.42-3.18)$ & 0.787 & $7.04(0.93-53.12)$ & 0.058 \\
\hline No & 1 (reference) & & 1 (reference) & & 1 (reference) & \\
\hline \multicolumn{7}{|c|}{ Having a relative/friend/neighbour who tested positive } \\
\hline Yes & $0.43(0.14-1.30)$ & 0.135 & $0.77(0.24-2.50)$ & 0.667 & $0.73(0.22-2.36)$ & 0.597 \\
\hline No & 1 (reference) & & 1 (reference) & & 1 (reference) & \\
\hline \multicolumn{7}{|l|}{ (3) Parents } \\
\hline Yes & $0.79(0.45-1.38)$ & 0.406 & $0.90(0.52-1.54)$ & 0.695 & $0.84(0.50-1.44)$ & 0.539 \\
\hline No & 1 (reference) & & 1 (reference) & & 1 (reference) & \\
\hline \multicolumn{7}{|l|}{ (4) Relatives } \\
\hline Yes & $0.44(0.25-0.79)$ & 0.006 & $0.76(0.44-1.29)$ & 0.307 & $0.50(0.29-0.86)$ & 0.012 \\
\hline
\end{tabular}

Males had at least twice the likelihood of having symptoms of depression and stress than females (AOR; 2.97 95\% CI, $1.61-5.48$ for depression; AOR, 1.90; 95\% CI, $1.07-3.35$ for stress). Finalists were less likely to have symptoms of depression and stress (AOR, 0.62; 95\% CI, $0.34-1.12$ ) and (AOR, 0.55; 95\% CI, $0.31-0.97$ for stress), respectively compared to the non-finalists. Individuals who had a leisure activity during the lock- down had an increased likelihood of having symptoms of depression and stress (AOR, 1.87; 95\% CI, 1.01 3.49 for depression; AOR, 1.98; 95\% CI, $1.10-3.56$ for stress). Using addictive substances was protective against all mental symptoms (AOR, 0.50; 95\% CI, 0.27 - 0.94 for higher levels of anxiety; AOR, 0.24; 95\% CI, $0.13-0.47$ for depression; AOR, 0.27; 95\% CI, 0.14 0.51 for stress). The detailed results of the multivariable analysis are shown in Table 3.

\section{Table 3: Multivariable Regression Analysis of Factors Associated with Symptoms of Depression, Anxiety, and Stress}

\begin{tabular}{|c|c|c|c|c|}
\hline \multirow[t]{2}{*}{ Variable } & \multicolumn{2}{|l|}{ Depression } & \multicolumn{2}{|l|}{ Stress } \\
\hline & AOR & P value & AOR & P value \\
\hline \multicolumn{5}{|l|}{ Sex } \\
\hline Male & $2.97(1.61-5.48)$ & 0.001 & $1.90(1.07-3.35)$ & 0.028 \\
\hline Female & 1 (reference) & & 1 (reference) & \\
\hline \multicolumn{5}{|l|}{ Finalist } \\
\hline Yes & $0.62(0.34-1.12)$ & 0.116 & $0.55(0.31-0.97)$ & 0.038 \\
\hline No & 1 (reference) & & 1 (reference) & \\
\hline \multicolumn{5}{|c|}{ Leisure activity involvement during lockdown } \\
\hline Yes & $1.87(1.01-3.49)$ & 0.047 & $1.98(1.10-3.56)$ & 0.023 \\
\hline No & 1 (reference) & & 1 (reference) & \\
\hline \multicolumn{5}{|l|}{ Substance use } \\
\hline Yes & $0.24(0.13-0.47)$ & $<0.001$ & $0.27(0.14-0.51)$ & $<0.001$ \\
\hline No & 1 (reference) & & 1 (reference) & \\
\hline
\end{tabular}

\section{Discussion}

This study investigated the prevalence and associated factors of symptoms of depression, anxiety, and stress among Ugandan University students during the lockdown, when learning was precipitously halted as a measure to reduce COVID 19 spread. The prevalence's of these mental symptoms were high, with three-quarters of the sample having symptoms; anxiety was highest, followed by depression, and then stress. Using addictive substances and being a finalist reduced the likelihood of having these mental symptoms. However, having a leisure activity during the lockdown and male sex were more associated with symptoms of stress and depression.
Almost all participants had severe levels of anxiety, indicating fear during this period mostly due to COVID-19 and fear of the unknown future; possibly, attributed to the high levels of misinformation ongoing during the pandemic ${ }^{38}$. The study findings are similar to a study done in a similar study group in Bangladeshi University students in May of 2020, with high prevalence symptoms of depression (82.4\%) and anxiety (87.7\%) (14). However, a systematic review of these mental symptoms in the general population with results published before May 2020 (early stages of the pandemic) indicated lower levels of stress (29.6\%), anxiety (31.9\%), and depression $(33.7 \%)^{39}$. This could be due to an increasing rate of mental symptoms in the general population, 
leading to a predicted pandemic of mental illness 9 , which other researchers have also predicted due to increasing mental symptoms as the pandemic progresses 10. This calls for more emphasis on students' mental health as the pandemic continues.

Male sex was associated with having symptoms of depression and stress, similar to a general population study during the pandemic that found more stressed and depressed males ${ }^{40}$. This was a surprising phenomenon seen in the pandemic because in Ugandan culture, with a notation of "men don't cry"; makes men not to typically open up about their mental symptoms as this is seen as a sign of weakness. This reporting could be attributed to the tool that was diverse and explored many symptoms leading to unmasking of the true mental symptoms experienced by these participants. With more males statistically having been more infected by COVID-19; this potentially puts them at high stress and fear of getting infected, hence the high levels of stress 10,41. Male students have also been found to not adhere to quarantine and protective measures as compared to females 38 , putting them at higher risk, thus, more fear and mental unwellness. Additionally, Uganda men, coping mechanisms for mental illness were eliminated during the pandemic such as freedom to move around, socialize, commune around shared interests, have agency, autonomy, among others. We suggest that, during the pandemic, more special attention should be given to male students given their poor mental health-seeking practices ${ }^{42}$. Culturally, males are more likely to engaged in substance abuse ${ }^{43}$.

Despite men having higher odds of mental symptoms; using substances of addiction such as alcohol in this study, reduced the likelihood to experience these symptoms. Could this paradoxical phenomenon of substance of addiction be a mode of self-medication to the symptoms experienced? as shown by previous studies, that these substances relieve depression and anxiety ${ }^{44,45}$. Many substances of addiction have a similar mode of action as antidepressants and anxiolytics, thereby potentially treating or resolving the symptoms of anxiety, depression, or stress these individuals had or could have had. More university students would be engaged in abuse/use of these substances due to high levels of boredom during the pandemic. With such high levels of mental illness symptoms, we could be having an increase in the number of dependences on addictive substances as the pandemic progresses, that is. the second pandemic of mental illness deliberating the most promising age and a group of the near future (university students).

Individuals who had any kind of leisure activity were also at a higher risk of stress and depression. This may be attributed to using them as a means of treating their mental symptoms. Previous research has indicated leisure activities such as exercise, yoga, watching movies, and singing can be used in the treatment of depression and stress ${ }^{46}$. Other studies have also shown that being involved in leisure activities lowers preventive behaviours thus putting them at more risk of getting COVID-19, thus more anxiety then stress and depression ${ }^{47}$.

Finalists had better mental health than other students, due to the government promising them an earlier resumption of schooling than other students since they were considered an essential group ${ }^{48}$. Thus, reducing fear of the unknown future among them. This was contradictory to previous a previous study that suggested these individuals to have higher levels of mental symptoms 26. The remaining Ugandan students may be in great fear and affected with great boredom hence higher levels, so engaging them in online learning may be the solution to combat these symptoms. Studies during the pandemic indicate that engaging students online comes with more advantages, such as, easy illustration, direct sharing with teachers, and less stressing due to each student learning at their own pace ${ }^{49}$.

\section{Strength and limitations}

The sample and study design may have influenced the proportions and the finding in the study. The major strength of our study was also conducted 4 months after lockdown of universities, a period that was full of uncertainty about going back to school or any linkage to their institutions, hence, more mental challenges, thus, the findings are a true representation of students' mental health challenges related to COVID-19.

Our study also had several limitations. First, this was an online survey using a convenience sampling method conducted in a period characterised by financial challenges and loss of employment opportunities hence we could have missed views of several students who were not able to access the internet and social media during the study period. Secondly, it involved self-reporting, thus leading to reporting and recall bias. Thirdly, the snapshot nature of the study limits our ability to determine the cause-effect relationship between different independent and outcome variables. We could not de- 
termine the true response rate based on the method we used to distribute the link (WhatsApp) and the google forms also do not track the number of individuals who view the link; thus, the recipients may not easily be determined. We cannot also guarantee that all the respondents are truly University students since the link was open to anyone who could access it. Lastly, we did not reach the desired minimum sample size after one month of data collection to ascertain sufficient power for the study and with half of the participants being medical students, hence making the results not generalisable. Despite these limitations, this was the available option since students were so dispersed and the universities were completely shut down.

\section{Conclusion}

The present study shows that more than three-quarters of university students are having mental symptoms of anxiety, depression, and stress during the COVID-19 to lock down their institutes because of the pandemic and the prevailing pandemic. Therefore, there is a need for interventions to support youth with more opportunities of engagement in productive activities to avoid participating in risky leisure activities or redundancy which increases their risk of having mental illness symptoms.

\section{Authors' contributions}

The study was Conceptualised by Mark Mohan Kaggwa and Sarah Maria Najjuka, design by all the authors. Analysis of the data performed by Mark Mohan Kaggwa. The initial draft produced by Mark Mohan Kaggwa, Sarah Maria Najjuka, and Gaudencia Checkwech. Critical revision of the manuscript performed by Ronald Olum and Scholastic Ashaba. All authors commented on previous versions of the manuscript. All authors read and approved the final manuscript.

\section{Acknowledgments}

Tonny Badambya, Nabatanza Brenda, Simpson Nuwamanya, Letizia Mary Atim, Sharon Bangi, Rahel Nkola, and Abel Rubega helped in distribution of the link. Associate professor Sheila Harms and Professor Streiner L David advised on the writing of the manuscript. On a special note, we would wish to acknowledge the late Felix Onyango Kijoki, who succumbed to COVID-19 (may his soul rest in peace), for his efforts in distributing the link to both national and international students. You will surely remain dear to our hearts and thanks for the fight against COVID-19 related mental health.

\section{References}

1. Lai CC, Shih TP, Ko WC, Tang HJ, Hsueh PR. Severe acute respiratory syndrome coronavirus 2 (SARS-CoV-2) and coronavirus disease-2019 (COVID-19): The epidemic and the challenges. Int J Antimicrob Agents. 2020;55(3):105924.

2. Spinelli A, Pellino G. COVID-19 pandemic: perspectives on an unfolding crisis. $\mathrm{Br} J$ Surg. 2020;107(7):785-7.

3. World health Organisation. Advice for the public on COVID-19 2020 [Available from: https:// www.who.int/emergencies/diseases/novel-coronavirus-2019/advice-for-public.

4. Kaggwa MM, Muwanguzi M, Nduhuura E, Kajjimu J, Arinaitwe I, Kule M, et al. Suicide among Ugandan university students: evidence from media reports for 2010-2020. BJPsych International. 2021;18(3):637.

5. Uganda Ministry of Health. Coronavirus disease (COVID-19) case confirmed 2020 [Available from: https://www.health.go.ug/document/coronavirus-disease-covid-19-case-confirmed/.

6. Olum R, Bongomin F. Uganda's first 100 COVID-19 cases: Trends and lessons. International Journal of Infectious Diseases. 2020;96.

7. Sahu P. Closure of Universities Due to Coronavirus Disease 2019 (COVID-19): Impact on Education and Mental Health of Students and Academic Staff. Cureus. 2020;12(4):e7541-e.

8. Worldometer. Coronavirus Death Toll and Trends-Worldometer. 2020 [Available from: https:// www.worldometers.info/coronavirus/coronavirus-death-toll/.

9. Choi KR, Heilemann MV, Fauer A, Mead M. A Second Pandemic: Mental Health Spillover From the Novel Coronavirus (COVID-19). J Am Psychiatr Nurses Assoc. 2020;26(4):340-3.

10. Shi L, Lu Z-A, Que J-Y, Huang X-L, Liu L, Ran M-S, et al. Prevalence of and Risk Factors Associated With Mental Health Symptoms Among the General Population in China During the Coronavirus Disease 2019 Pandemic. JAMA Network Open. 2020;3(7):e2014053-e. 11. Al Mamun F, Hosen I, Misti JM, Kaggwa MM, Mamun MA. Mental Disorders of Bangladeshi Students During the COVID-19 Pandemic: A Systematic Review. Psychol Res Behav Manag. 2021;14:645-54.

12. Zhang SX, Wang Y, Rauch A, Wei F. Unprecedented disruption of lives and work: Health, distress and life satisfaction of working adults in China one month into the COVID-19 outbreak. Psychiatry Res. 2020;288:112958. 
13. Marelli S, Castelnuovo A, Somma A, Castronovo V, Mombelli S, Bottoni D, et al. Impact of COVID-19 lockdown on sleep quality in university students and administration staff. J Neurol. 2021;268(1):8-15.

14. Islam S, Akter R, Sikder T, Griffiths MD. Prevalence and Factors Associated with Depression and Anxiety Among First-Year University Students in Bangladesh: A Cross-Sectional Study. International Journal of Mental Health and Addiction. 2020.

15. Bono G, Reil K, Hescox J. Stress and wellbeing in college students during the COVID-19 pandemic: Can grit and gratitude help? International Journal of Wellbeing. 2020;10:39-57.

16. Odriozola-González P, Planchuelo-Gómez Á, Irurtia MJ, de Luis-García R. Psychological effects of the COVID-19 outbreak and lockdown among students and workers of a Spanish university. Psychiatry Res. 2020;290:113108-.

17. Kajjimu J, Kaggwa MM, Bongomin F. Burnout and Associated Factors Among Medical Students in a Public University in Uganda: A Cross-Sectional Study. Adv Med Educ Pract. 2021;12:63-75.

18. Kaggwa MM, Nuwamanya S, Ashaba S, Rukundo GZ, Harms S. An Adolescent's Use of Veterinary Medicines: A Case Report Exploring Addiction. Journal of Psychoactive Drugs. 2021:1-6.

19. Vargas-Huicochea I, Álvarez-del-Río A, Rodríguez-Machain AC, Aguirre-Benítez EL, Kelsall N. Seeking Psychiatric Attention Among University Students with Mental Health Problems: the Influence of Disease Perception. International Journal of Mental Health and Addiction. 2020.

20. Rahman ME, Saiful Islam M, Mamun MA, Moonajilin MS, Yi S. Prevalence and Factors Associated with Suicidal Ideation Among University Students in Bangladesh. Archives of suicide research: official journal of the International Academy for Suicide Research. 2020:1-10.

21. Kaggwa MM, Kajjimu J, Sserunkuma J, Najjuka SM, Atim LM, Olum R, et al. Prevalence of burnout among university students in low- and middle-income countries: A systematic review and meta-analysis. PLOS One. 2021;16(8): 0256402.

22. Kaggwa MM, Bongomin F, Najjuka SM, Rukundo GZ, Ashaba S. Cannabis-induced mania following CoViD-19 self-medication: a wake-up call to improve community awareness. International Medical Case Reports Journal. 2021;14:121.

23. Cao W, Fang Z, Hou G, Han M, Xu X, Dong J, et al. The psychological impact of the COVID-19 epidemic on college students in China. Psychiatry Res. 2020;287:112934.

24. Liu X, Liu J, Zhong X. Psychological State of
College Students During COVID-19 Epidemic. SSRN Electronic Journal. 2020.

25. Tang W, Hu T, Hu B, Jin C, Wang G, Xie C, et al. Prevalence and correlates of PTSD and depressive symptoms one month after the outbreak of the COVID-19 epidemic in a sample of home-quarantined Chinese university students. Journal of Affective Disorders. 2020;274:1-7.

26. Lee J. Mental health effects of school closures during COVID-19. Lancet Child Adolesc Health. 2020;4(6):421-.

27. Czeisler MÉ, Lane RI, Petrosky E, Wiley JF, Christensen A, Njai R, et al. Mental Health, Substance Use, and Suicidal Ideation During the COVID-19 Pandemic - United States, June 24-30, 2020. MMWR Morb Mortal Wkely Rep. 2020;69(32):1049-57.

28. Yehudai M, Bender S, Gritsenko V, Konstantinov V, Reznik A, Isralowitz R. COVID-19 Fear, Mental Health, and Substance Misuse Conditions Among University Social Work Students in Israel and Russia. International Journal of Mental Health and Addiction. 2020. 29. Gritsenko V, Skugarevsky O, Konstantinov V, Khamenka N, Marinova T, Reznik A, et al. COVID 19 Fear, Stress, Anxiety, and Substance Use Among Russian and Belarusian University Students. International Journal of Mental Health and Addiction. 2020:1-7.

30. Zolotov Y, Reznik A, Bender S, Isralowitz R. COVID-19 Fear, Mental Health, and Substance Use Among Israeli University Students. Int J Ment Health Addict. 2020:1-7.

31. Mboya IB, John B, Kibopile ES, Mhando L, George J, Ngocho JS. Factors associated with mental distress among undergraduate students in northern Tanzania. BMC Psychiatry. 2020;20(1):28.

32. Hernández-Torrano D, Ibrayeva L, Sparks J, Lim N, Clementi A, Almukhambetova A, et al. Mental Health and Well-Being of University Students: A Bibliometric Mapping of the Literature. Front Psychol. 2020;11:1226-.

33. Ministry of education and sports. Ministry of Education and Sports, Uganda. Ministry of Education and Sports 2020 [Available from: http://www.education.go.ug/.

34. Lovibond PF, Lovibond SH. The structure of negative emotional states: comparison of the Depression Anxiety Stress Scales (DASS) with the Beck Depression and Anxiety Inventories. Behav Res Ther. 1995;33(3):335-43.

35. Tan BYQ, Chew NWS, Lee GKH, Jing M, Goh Y, Yeo LLL, et al. Psychological Impact of the COVID-19 Pandemic on Health Care Workers in Singapore. Ann Intern Med. 2020;173(4):317-20. 
36. Wang C, Pan R, Wan X, Tan Y, Xu L, Ho CS, et al. Immediate Psychological Responses and Associated Factors during the Initial Stage of the 2019 Coronavirus Disease (COVID-19) Epidemic among the General Population in China. Int J Environ Res Public Health. 2020;17(5).

37. Smith Z. Construct validation of the DASS-21 in a non-clinical sample of working adults: University of Johannesburg (South Africa); 2017.

38. Sallam M, Dababseh D, Yaseen A, Al-Haidar A, Ababneh NA, Bakri FG, et al. Conspiracy Beliefs Are Associated with Lower Knowledge and Higher Anxiety Levels Regarding COVID-19 among Students at the University of Jordan. Int J Environ Res Public Health. 2020;17(14).

39. Salari N, Hosseinian-Far A, Jalali R, Vaisi-Raygani A, Rasoulpoor S, Mohammadi M, et al. Prevalence of stress, anxiety, depression among the general population during the COVID-19 pandemic: a systematic review and meta-analysis. Globalization and Health. 2020;16(1):57.

40. Gao W, Ping S, Liu X. Gender differences in depression, anxiety, and stress among college students: A longitudinal study from China. Journal of Affective Disorders. 2020;263:292-300.

41. Jin JM, Bai P, He W, Wu F, Liu XF, Han DM, et al. Gender Differences in Patients With COVID-19: Focus on Severity and Mortality. Front Public Health. 2020;8:152.

42. Sagar-Ouriaghli I, Godfrey E, Bridge L, Meade L, Brown JSL. Improving Mental Health Service Utilization Among Men: A Systematic Review and Syn- thesis of Behavior Change Techniques Within Interventions Targeting Help-Seeking. Am J Mens Health. 2019;13(3):1557988319857009.

43. Wagman JA, Nabukalu D, Miller AP, Wawer MJ, Ssekubugu R, Nakowooya H, et al. Prevalence and correlates of men's and women's alcohol use in agrarian, trading and fishing communities in Rakai, Uganda. PLoS One. 2020;15(10):e0240796.

44. Bolton J, Cox B, Clara I, Sareen J. Use of alcohol and drugs to self-medicate anxiety disorders in a nationally representative sample. J Nerv Ment Dis. 2006;194(11):818-25.

45. Leeies M, Pagura J, Sareen J, Bolton JM. The use of alcohol and drugs to self-medicate symptoms of posttraumatic stress disorder. Depress Anxiety. 2010;27(8):731-6.

46. Schuch FB, Bulzing RA, Meyer J, Vancampfort D, Firth J, Stubbs B, et al. Associations of moderate to vigorous physical activity and sedentary behavior with depressive and anxiety symptoms in self-isolating people during the COVID-19 pandemic: A cross-sectional survey in Brazil. Psychiatry Res. 2020;292:113339.

47. Kim YJ, Cho JH. Correlation between Preventive Health Behaviors and Psycho-Social Health Based on the Leisure Activities of South Koreans in the COVID-19 Crisis. Int J Environ Res Public Health. 2020;17(11). 48. Uganda Radio Network. Schools allowed to reopen for final-year health students. 2020 [Available from: https://observer.ug/news/headlines/66408-schoolsallowed-to-reopen-for-final-yearhealth-students.

49. Tropea M, De Rango F. COVID-19 in Italy: current state, impact and ICT-based solutions. IET Smart Cities. 2020;2(2):74-81. 